\title{
SYNTHESIS OF LIQUID MENTHOL BY HYDROGENATION OF DEMENTHOLIZED PEPPERMINT OIL OVER Ni CATALYSTS
}

\author{
Debora L. Manuale, Carolina Betti, Alberto J. Marchi y Juan C. Yori* \\ Instituto de Investigaciones en Catálisis y Petroquímica, Facultad de Ingeniería Química, Universidad Nacional del Litoral, Concejo \\ Nacional de Investigaciones Científicas y Técnicas, Santiago del Estero 2654, 3000 Santa Fe, Argentina \\ Eva Romeo \\ Departamento de Ingeniería Química y Ambiental, Facultad de Ciencias, Universidad de Zaragoza, 50009 Zaragoza, España
}

Recebido em 5/1/09; aceito em 18/2/10; publicado na web em 3/5/10

\begin{abstract}
Hydrogenation of (-)-menthone and (+)-isomenthone was studied at $2.7 \mathrm{MPa}$ and $100{ }^{\circ} \mathrm{C}$. The objective was to produce a liquid menthol mixture rich in (-)-menthol from dementholized peppermint oil. Ni-based catalysts were tested and compared for this reaction: a) 6 and 12\% Ni dispersed into a nonstoichiometric magnesium aluminate (Ni-Mg-Al) with spinel structure; b) Ni-Raney catalyst. Both types of catalysts were active for (-)-menthone and (+)-isomenthone hydrogenation. Lower conversion but higher selectivity to (-)-menthol was obtained with Ni-Mg-Al catalysts. However, they rapidly lost their activity. Instead Ni-Raney catalysts kept its original activity even after several hydrogenation runs.
\end{abstract}

Keywords: selective hydrogenation; liquid menthol; Ni catalysts.

\section{INTRODUCTION}

2-Isopropyl-5-methyl-cyclohexanol (menthol) is a monoterpene, that has four stereoisomers: menthol, isomenthol, neomenthol and neoisomenthol. In turn each of these stereoisomers has two optic isomers (levogirous and dextrogirous forms) yielding a total number of eight menthol isomers. These eight optically active isomers have organoleptic differences between them. (-)-Menthol is the isomer of highest commercial value due to its highly refreshing action. It is widely used in the fragrance, pharmacy and flavour industries and is the main component of the Arvensis peppermint oil. This oil is the main natural source of menthol and is recovered by steam distillation of the liquid contained in peppermint leaves. (-)-Menthol is obtained from this recovered oil using a low temperature crystallization process. This product is centrifuged to remove the non-crystallizing liquid fraction and then the solid fraction is dried at low temperatures. The whole process takes 25-30 days in a refrigerated chamber. Not all the (-)-menthol in the peppermint oil crystallizes and, as a consequence, one liquid subproduct is obtained; the so-called "dementholized peppermint oil". This product has a low commercial value in spite of having an important content of (-)-menthol (approximately 35-45\%), (+)-neomenthol (11-15\%), (-)-menthone (25-30\%) and (+)-isomenthone (12-18\%). ${ }^{1}$

(-)-Menthol has a fusion point of $42-44{ }^{\circ} \mathrm{C}$, i.e. it is normally solid at room temperature. Due to this low fusion point menthol is traded and transported in closed vessels. This makes the product more expensive besides of being an ineffective storing method for long transportation and storing periods. Besides, it is lost by sublimation during packing and the low density of the menthol crystals increases the transportation costs. For these reasons the main firms producing (-)-menthol in the world are actively seeking for new ways of distributing menthol. One such way is the production of liquid menthol. ${ }^{2}$ Liquid menthol advantageously replaces the needle-like crystals of solid menthol because it has no handling transportation or storage problems and it does not need to be fused or dissolved to be used in the final formulation. Table 1 shows the composition of different peppermint oils and liquid menthol.

*e-mail: jyori@ fiq.unl.edu.ar
Table 1. Typical oil percent composition

\begin{tabular}{lccc}
\hline & $\begin{array}{c}\text { Virgin peppermint } \\
\text { oil (\%) }\end{array}$ & $\begin{array}{c}\text { Dementholized } \\
\text { peppermint oil (\%) }\end{array}$ & $\begin{array}{c}\text { Liquid Menthol } \\
(\%)\end{array}$ \\
\hline Other Terpenes & 3.3 & 6.0 & 0 \\
(-)-Menthone & 9.8 & 26.2 & \\
(+)-Isomenthone & 5.0 & 14.7 & \\
Total Menthone & 14.8 & 40.9 & $<1.0$ \\
(-)-Menthol & 77.1 & 41.1 & 70.0 \\
(+)-Neomenthol & 4.3 & 11.4 & \\
(-)-Isomenthol & 0.5 & 0.6 & \\
(+)-Neoisomenthol & - & - & \\
Total Menthol & 81.9 & 53.1 & $>90.0$ \\
\hline
\end{tabular}

In previous papers, ${ }^{3,4}$ we confirmed that the catalytic hydrogenation of the (-)-menthone and the (+)-isomenthone fraction remaining in dementholized peppermint oil can transform this substances into (-)-menthol and its isomers thus upgrading a residue of low cost into a product of high commercial value. (-)-Menthone in dementholized peppermint oil can be hydrogenated to produce a mixture of (-)-menthol and (+)-neomenthol. From an industrial point of view this hydrogenated product could be used as an alternative to solid (-)-menthol crystals in the preparation of different products. Besides the additional amounts of (-)-menthol produced by hydrogenation, distillation and crystallization would increase the yield of menthol from peppermint oil. Menthol produced by hydrogenation would result to be cheaper than that produced by extraction from virgin peppermint oil.

Several processes for the preparation of (-)-menthol from compounds which have the carbon skeleton of menthane containing at least one $\mathrm{C}=\mathrm{C}$ bond and are 3 -substituted by oxygen for example: menthone, isomenthone, thymol and their mixtures, are described in different reports. ${ }^{5-8} \mathrm{Ni}$ Raney was frequently used as a hydrogenation catalysts even when it presents several disadvantages. It is not the most user friendly in terms of operation and environmental care. Its final disposal is very complicated. Then, it is necessary to develop better hydrogenation catalysts. 
Recently, Ravasio et al. had published very promising results of dementholized cornmint hydrogenation using $\mathrm{Cu} / \mathrm{Al}_{2} \mathrm{O}_{3}$ catalysts. ${ }^{9}$

Figure 1 shows the reaction pathways for the hydrogenation of (-)-menthone and (+)-isomenthone. ${ }^{10}$ The desired product, (-)-menthol, is produced by the reduction of the carbonyl group of (-)-menthone and (+)-neomenthol is produced as a subproduct. (+)-Isomenthone is hydrogenated to (-)-isomenthol and (+)-neoisomenthol. (-)-Isomenthol is specially undesirable because it gives an ugly flavour and odour to the mixture of menthol.<smiles>CC(C)[C@H]1CC[C@@H](C)CC1=O</smiles>

(+) isomenthone
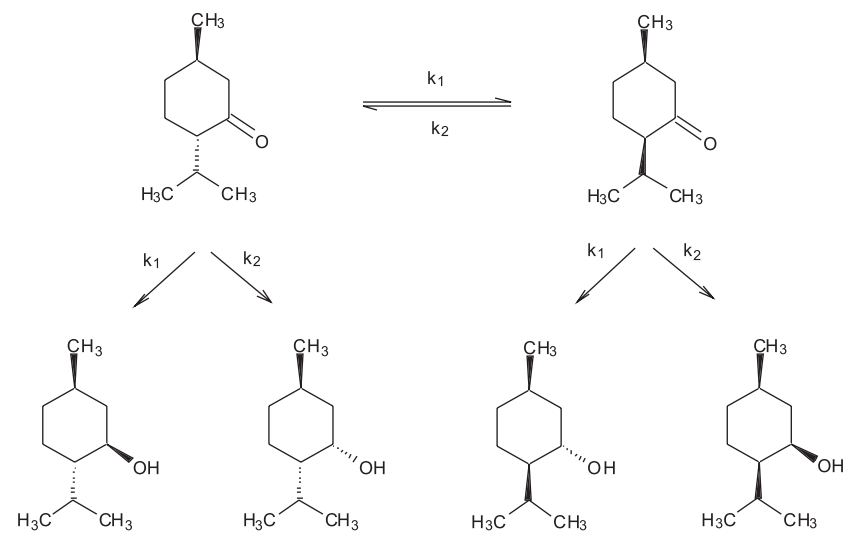

(-) menthol

(+) neomenthol

$(-)$ isomenthol

(+) neoisomenthol

Figure 1. Reaction pathways for the hydrogenation of (-)-menthone and (+)-isomenthone

The aim is to obtain a menthol rich fraction whose composition is as close as possible to that of what is known at the market as Liquid Menthol. The study the hydrogenation of (-)-menthone and $(+)$-isomenthone present in dementholized peppermint oil by catalytic reduction over nickel based catalysts was performed. Two different $\mathrm{Ni}$ catalysts were tested: Ni-Raney and Ni supported over a magnesium aluminate with spinel structure.

\section{EXPERIMENTAL}

\section{Catalysts preparations}

The catalysts used were of two basic kinds: a) a commercial Ni Raney catalyst (BASF katalysator H 150) supplied by BASF Aktiengesellschaft; b) two Ni-Mg-Al catalysts, prepared by coprecipitation at $60{ }^{\circ} \mathrm{C}$ and a $\mathrm{pH}$ value of 10 . After the coprecipitation stage, the catalysts were dried in a stove at $80^{\circ} \mathrm{C}$ and they were then decomposed in a nitrogen stream at $500{ }^{\circ} \mathrm{C} .{ }^{11}$

\section{Catalysts characterization}

The elemental composition of the Ni-Mg-Al catalysts was determined by atomic absorption spectrometry (AA). The specific surface area was measured in a Micromeritics $2100 \mathrm{E}$ equipment by taking nitrogen adsorption isotherms at $-196^{\circ} \mathrm{C}$. Previously the samples were degassed for $2 \mathrm{~h}$ in vacuo at $200{ }^{\circ} \mathrm{C}$.

The crystalline structure was determined by X-ray diffraction in a Shimadzu DX-1 apparatus using $\mathrm{Cu} \mathrm{K} \alpha$ radiation filtered with $\mathrm{Ni}$. The spectrum was recorded in the $20-65^{\circ} 2 \theta$ range with a scanning rate of $2^{\circ} \mathrm{min}^{-1}$. The reducibility of the samples was determined by temperature programmed reduction (TPR) in an Ohkura TP2002 equipment having a thermal conductivity detector. The samples were stabilized in $\mathrm{Ar}$ at room temperature and then they were heated to
$850{ }^{\circ} \mathrm{C}$ in a reducing gas mixture $\left(4.8 \% \mathrm{H}_{2}\right.$ in $\left.\mathrm{Ar}\right)$ with a heating rate of $10{ }^{\circ} \mathrm{C} \mathrm{min}{ }^{-1}$. The dispersion of the metal phase was measured in a Micromeritics 2100E equipment. The samples were reduced at different temperatures in hydrogen for $1 \mathrm{~h}$. Then they were degassed at the same temperature for $2 \mathrm{~h}$ in a vacuum of $10^{-5}$ Torr. Both the isotherms of total adsorption and reversible adsorption were measured at room temperature. Irreversibly chemisorbed hydrogen was obtained by substracting both isotherms and extrapolating to zero pressure. Finally the metal dispersion was obtained by assuming dissociative adsorption of hydrogen on the $\mathrm{Ni}$ surface atoms and a stoichiometry of $\mathrm{H} / \mathrm{Ni}=1$.

\section{Catalytic activity tests}

Hydrogenation reactions were performed in a stainless steel stirred batch reactor with stirring and heating systems capable of working at pressures as high as 100 bar. The reactor had internal baffles and a stirring rate control for 100-1500 rpm. In each run 10 $\mathrm{mL}$ of dementholized peppermint oil (whose composition is indicated in Table 1), $90 \mathrm{~mL}$ of solvent (2-propanol) and $1 \mathrm{~g}$ of the catalyst were charged to the reactor. Before starting the reaction the reactor was flushed with hydrogen in order to eliminate all traces of oxygen. Then the reactor was heated to the reaction temperature, $100^{\circ} \mathrm{C}$, and the pressure was raised to $2.7 \mathrm{MPa}$. When the tank began to be stirred the reaction was assumed to begin.

In order to verify that diffusional restrictions do not modify catalytic measurements, experiments varying stirrer speed and particle size were carried out. It was determined that no apparent difussion control is influencing the overall rate and selectivity when using stirrer speeds higher than $700 \mathrm{rpm}$ and particles sizes lower than $100 \mu \mathrm{m}$. Furthermore, reactor was designed with an efficient sampling system which prevents typical problems of flash evaporation. Samples were taken at different values of reaction time and they were analyzed off-situ by gas chromatography in a Varian Star 3400CX equipment with a flame ionization detector and a ZB-Wax capillary column. The formation of (-)-menthol or ( \pm )-menthol was confirmed by analyzing several samples with a 30m Supelco $\alpha$-DEX capillary column, in order to be able to resolve optical isomers.

Total conversion and selectivity from (-)-menthone to (-)-menthol were calculated with Equations 1 and 2 assuming the reaction took place according to the mechanism proposed by Besson et al.. ${ }^{10}$ (Figure 1).

Total conversion $=(\mathrm{MN}+\mathrm{IMN})_{\mathrm{HO}} /(\mathrm{MN}+\mathrm{IMN})_{\text {DMо }}$

$\mathrm{MN}$-to-ML selectivity $=\left(\mathrm{ML}_{\mathrm{HO}}-\mathrm{ML}_{\mathrm{DMO}}\right) /\left(\mathrm{MN}_{\mathrm{DMO}}-\mathrm{MN}_{\mathrm{HO}}\right)$

where: MN: (-)-menthone content in the mixture (mass \%); IMN: (+)-isomenthone content in the mixture (mass \%); ML: (-)-menthol content in the mixture (mass \%); DMO: dementholized peppermint oil; HO: hydrogenated oil.

\section{RESULTS AND DISCUSSION}

\section{Physicochemical characterization}

The Ni-Mg-Al samples treated at $500{ }^{\circ} \mathrm{C}$ in $\mathrm{N}_{2}$ were characterized by XRD (Figure 2) and TPR (Figure 3). In the Ni(6\%)-Mg-Al and $\mathrm{Ni}(12 \%)-\mathrm{Mg}-\mathrm{Al}$ samples the combined use of XRD and TPR allowed to detect at least two phases. The results obtained by XRD clearly show that $\mathrm{NiO}$ was the main phase present. The crystallite size, determined by the Debye-Scherrer Equation, was between 4-5 $\mathrm{nm}$. This value lies in the detection limit of these technique. To a lower 
extent a poorly crystallized spinel structure could also be detected. This phase could be a non-stoichiometric magnesium aluminate of high specific surface area (250-280 $\left.\mathrm{m}^{2} \mathrm{~g}^{-1}\right)$ according to the data obtained by B.E.T. method.

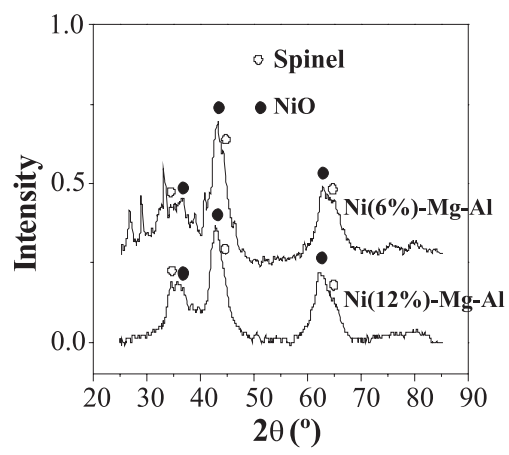

Figure 2. XRD spectra of the Ni-Mg-Al catalysts

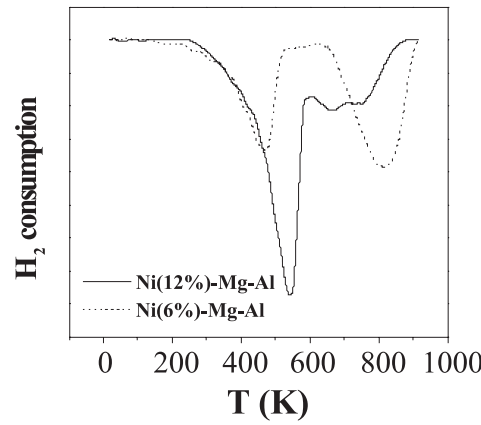

Figure 3. TPR traces of the Ni-Mg-Al mixed oxide catalysts

The TPR traces show at least two peaks of hydrogen consumption in the Ni-Mg-Al samples: one at $460-530^{\circ} \mathrm{C}$ attributed to the reduction of small $\mathrm{NiO}$ particles highly dispersed in the $\mathrm{Ni}-\mathrm{Mg}$ - $\mathrm{Al}$ matrix and another one at $670-800^{\circ} \mathrm{C}$ attributed to the reduction of $\mathrm{Ni}^{2+}$ strongly interacting with $\mathrm{Mg}$ aluminate spinel phase. ${ }^{11} \mathrm{In}$ both cases the peaks are in fact broad $\mathrm{H}_{2}$ consumption bands. The first one begins at about $300{ }^{\circ} \mathrm{C}$ and the second at temperatures higher than $600^{\circ} \mathrm{C}$. If we considers the high-temperature reduction peak, the maximum $\mathrm{H}_{2}$ uptake is observed at higher temperature for the $\mathrm{Ni}(6 \%)-\mathrm{Mg}$ - $\mathrm{Al}$ mixed oxide than for $\mathrm{Ni}(12 \%)-\mathrm{Mg}-\mathrm{Al}$. Besides, the ratio of the intensity of the high reduction peak respect to the low-temperature peak was higher for $\mathrm{Ni}(6 \%)-\mathrm{Mg}-\mathrm{Al}$ than for $\mathrm{Ni}(12 \%)-\mathrm{Mg}-\mathrm{Al}$ sample. Both facts are indicative that interaction of $\mathrm{Ni}^{+2}$ ions with the spinel phase is much stronger in $\mathrm{Ni}(6 \%)-\mathrm{Mg}-\mathrm{Al}$ than in $\mathrm{Ni}(12 \%)-\mathrm{Mg}-\mathrm{Al}$.

After reducing in hydrogen at different temperatures the capacity for hydrogen chemisorption on the $\mathrm{Ni}-\mathrm{Mg}-\mathrm{Al}$ samples was assessed. In all cases the fraction of metallic $\mathrm{Ni}$ exposed on the surface was equal or lower than $5 \%$. Surprisingly metal dispersion increased when the temperature of reduction was raised. This effect could be attributed to $\mathrm{Ni}^{2+}$ being reduced to $\mathrm{Ni}^{0}$ more easily at higher temperatures, according to the TPR tests. This effect would be stronger than the loss of dispersion by sintering at higher temperatures. This dispersiontemperature pattern also indicates that metallic nickel species are in strong interaction with the $\mathrm{Mg}$ aluminate spinel matrix and therefore their sintering is inhibited.

The results show that in the Ni-Mg-Al samples Ni is initially in the form of small $\mathrm{NiO}$ crystallites and also $\mathrm{Ni}^{2+}$ dispersed in a $\mathrm{Mg}$ aluminate spinel. Both $\mathrm{Ni}$ species are in strong interaction with the support. As a result hydrogen activation produces sintering resistant nickel metal particles.

\section{Catalytic tests}

Figure 4 shows the results of total conversion of the mixture of (-)-menthone and (+)-isomenthone and the selectivity to (-)-menthol calculated with Equations 1 and 2. Conversion and selectivity are plotted as a function of time for the Ni Raney, $\mathrm{Ni}(12 \%) \mathrm{MgAl}$ and $\mathrm{Ni}(6 \%) \mathrm{MgAl}$ catalysts. In general, the products of the hydrogenation of (-)-menthone are (-)-menthol and (+)-neomenthol while (+)-neoisomenthol and (-)-isomenthol are produced from (+)-isomenthone (Figure 1). No formation of the other enantiomers was detected.
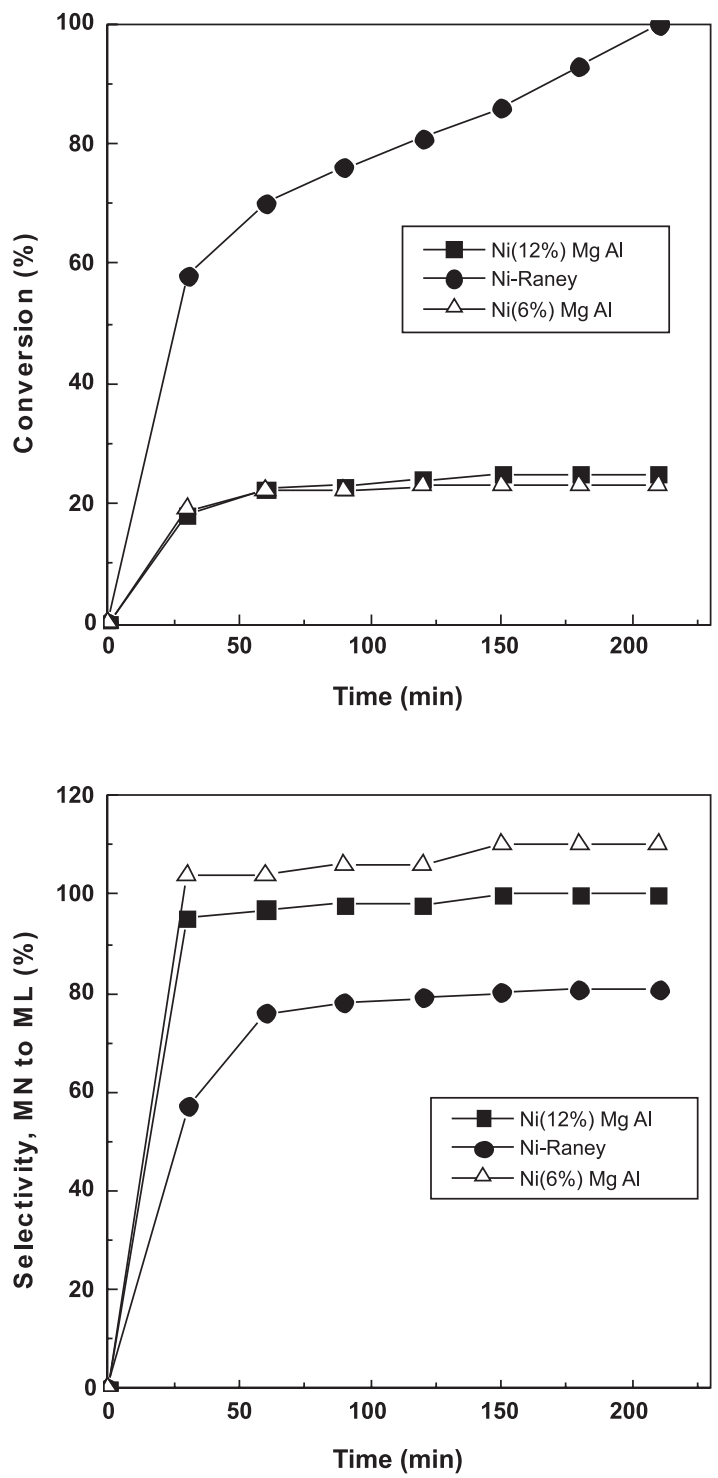

Figure 4. Total conversion and selectivity to (-)-menthol as a function of time

In the case of Ni Raney a continuous growth of the conversion with reaction time was found. At $3.5 \mathrm{~h}$ a $100 \%$ conversion of the ((-)-menthone and (+)-isomenthone) is obtained. The final product had the following composition: $63.4 \%(-)$-menthol, $18.7 \%(+)$-neomenthol, $17.9 \%$ (+)-neoisomenthol. No (-)-isomenthol was found. The total content of menthols was greatly increased from a $53.1 \%$ for dementholized oil to a $100 \%$ for the the hydrogenated oil. 
The selectivity values for the conversion of (-)-menthone to (-)-menthol vary between $60-80 \%$ (Figure 4). The selectivity to each isomer was not modified with conversion, indicating that under the reaction conditions used there is no isomerization of the menthols. Isomerization of menthols can be catalyzed by sodium methoxide or hydrogenation catalysts at temperatures higher than $180{ }^{\circ} \mathrm{C}$. Since no isomerization takes place in our case the products are nonequilibrium mixtures. An equilibrium mixture has the composition: 62\% (-)-menthol, 23\% (+)-neomenthol, 12\% (-)-isomenthol and 3\% (+)-neoisomenthol. ${ }^{12}$ When the catalyst is used again in a new run a similar reaction pattern is found, with almost equal conversion and selectivity values as a function of time, indicating that the catalyst has a stable activity.

The Ni-Mg-Al catalysts had a very different behavior. The total conversion increases up to a value of $20-22 \%$ and then remains constant. This indicates that the catalyst loses its hydrogenating activity during the first hour of the reaction. The deactivation process is fast in both cases, regardless of the metal load. However is important to remark that these catalyst have an unusually high selectivity for the production of (-)-menthol from (-)-menthone. $\mathrm{Ni}(12 \%) \mathrm{MgAl}$ shows selectivity of $98-100 \%$ while $\mathrm{Ni}(6 \%) \mathrm{MgAl}$ shows values higher than $100 \%$. The last values were confirmed with a mass balance and can be due to the combined effect of two factors: a) isomerization of (+)-isomenthone to (-)-menthone; b) selective hydrogenation of (-)-menthone to (-)-menthol.

Kukula et al. found no isomerization for temperatures as high as $200{ }^{\circ} \mathrm{C}$ but they used modified Ni Raney catalysts..$^{13}$ In our case is possible that isomerization is favored by the acid/base properties of the non-stoichiometric $\mathrm{Ni}-\mathrm{Mg}$-Al spinel. ${ }^{14,15}$ The influence of the acidbase sites on the isomerization of (+)-isomenthone into (-)-menthone could be favored by the high $\mathrm{Ni}^{+2}$ spinel interaction. In agreement with this argument, the $\mathrm{Ni}(6 \%)-\mathrm{Mg}-\mathrm{Al}$ catalyst, which has the higher $\mathrm{Ni}^{+2}$ spinel interaction, showed the highest selectivity to (-)-menthol.

\section{CONCLUSIONS}

Both Ni-Raney and Ni-Mg-Al catalysts were found to be active for the hydrogenation of dementholized peppermint oil to menthol. Mixtures free of isomenthol, an undesirable product, were always ob- tained. Ni-Raney was more active and stable than Ni-Mg-Al. However the $\mathrm{Ni}-\mathrm{Mg}$-Al catalysts produced the isomerization of (+)-isomenthone to (-)-menthone, leading to about $100 \%$ selectivity to (-)-menthol from (-)-menthone. The high selectivity was attributed to the interaction of nickel with a spinel-like phase in the $\mathrm{Ni}-\mathrm{Mg}$-Al catalysts.

\section{ACKNOWLEDGMENTS}

The authors thank CONICET and Deputy Chamber of Santa Fe-Argentina for their financial support to this work.

\section{REFERENCES}

1. Lopez, M.; Allinger, N.; Química Orgánica, Reverte, 1979, p. 155.

2. Yamamoto, T.; Ohta, H.; U.S. Patent 5,663,460, 1997, to Takasago International Corporation.

3. Yori, J. C.; Manuale, D. L.; Marchi, A. J.; Grau, J. M.; Appl. Catal., A 2004, 275, 221.

4. Marchi, A. J.; Grau, J. M. ; Yori, J. C.; Appl. Catal., A 2004, 275, 227.

5. Galo Cárdenas, T.; Oliva, R.; Reyes, P.; J. Chil. Chem. 2006, 51, 1053.

6. Ravi, P.; Ravichandram, R.; Divakar, S.; J.Mol. Catal. A: Chem. 1999, 148, 145.

7. Darsow, G.; Petruck, G.; U.S. Patent $N^{\circ} 5,750,803$, 1998, to Bayer Aktiengesellschaft.

8. Langer, R.; Petruck, G.; U.S. Patent $N^{\circ} 6,429,633,2002$, to Bayer Aktiengesellschaft.

9. Ravasio, N.; Zaccheria, F.; Fusi, A.; Psaro, R.; Appl. Catal.. A 2006, 315, 114.

10. Besson, M.; Bullivant, L.; Nicolaus-Dechamp, N.; Gallezot, P.; Stud. Surf. Sci. Catal. 1993, 78, 1155

11. Marchi, A. J.; Garetto, T. F.; Salamone, C.; Romeo, E.; Monzón, A.; Actas del XIX Simposio Iberoamericano de Catálisis, Mérida, México, 2004.

12. Tungler, A.; Mathe, T.; Bende, Z.; Petro, J.; Appl. Catal. 1985, 19, 365.

13. Kukula, P.; Cerveny, P.; Appl. Catal., A 2000, 193, 285.

14. Perez-Lopez, O. W.; Senger, A.; Marcillo, N. R.; Lansarin, M. A.; Appl. Catal., A 2006, 303, 234

15. Dussault, L.; Dupin, J. C.; Dumitrie, E.; Auroux, A.; Guimon, C.; Therm. Acta 2005, 434, 93 